\title{
Experimental Study on Influence of Ultra-fine Cement Content on Mechanical Properties of Modified Sludge
}

\author{
Shuren Wang ${ }^{1,2 *}$, Jialin Wei ${ }^{1}$, Xinyu Wang ${ }^{1}$ and Jian Wang ${ }^{1}$ \\ ${ }^{1}$ International Joint Research Laboratory of Henan Province for Underground Space Development and Disaster Prevention, \\ Henan Polytechnic University, Jiaozuo 454003, China \\ ${ }^{2}$ School of Minerals and Energy Resources Engineering, University of New South Wales, Sydney, NSW 2052, Australia
}

Received 3 February 2021; Accepted 21 April 2021

\begin{abstract}
To improve the bearing capacity of foundation with larger thickness of sludge layer, the foundation pit sludge in Fuzhou in China was regarded as the engineering background, the ultra-fine Portland cement as the sludge curing material was adopted and a series of tests were carried out, such as unconfined compressive strength, unconsolidated undrained triaxial shear, mercury intrusion porosimetry and scanning electron microscopy. The influence of ultra-fine cement content on the mechanical properties and microstructure of the modified sludge were investigated by fixing the total cement content at $20 \%$ and making the ultra-fine Portland cement gradually replace ordinary Portland cement in a $5 \%$ gradient. Results show that the unconfined compressive strength, cohesion and internal friction angle of the modified sludge increase linearly with the increase of the ultra-fine cement content. The increase in the content of the ultra-fine cement enhances the rate and adequacy of the hydration reaction of the cement, which not only improves the strength of the modified sludge as a whole, but also has a particularly obvious effect on the early strength of the modified sludge. The ultra-fine cement content has a greater effect on the amount of CSH gel generation. The reduction of microscopic pore size, the improvement of denseness and the enhancement of wholeness of the modified sludge soil body are the essential reasons for the effect of the ultra-fine cement on the mechanical properties of the modified sludge. The conclusions obtained in this study can expand the direction for the application of the ultra-fine cement and the selection of the sludge curing materials.
\end{abstract}

Keywords: Sludge, Ultra-fine cement, Mechanical properties, Microstructure, Modification

\section{Introduction}

In recent years, the urbanization process in China has been accelerating. With urban construction in full swing, more and more large foundation pits in coastal areas of China are inevitably located in geological environment with large thickness of sludge layer. Sludge is a soft soil with high water content, high compressibility, high sensitivity and low strength [1], which is susceptible to engineering hazards such as consolidation deformation and seismic subsidence when subjected to upper loads and mechanical vibrations during construction. This will not only bring harm to project quality and construction safety, but also cause damage to the adjacent buildings. In actual engineering, the silty clay shows that the bearing capacity of the foundation is relatively small, and it takes a long time to compress and stabilize under the load, and it will produce larger final settlement and uneven settlement. Therefore, it is usually necessary to modify the silt in advance to improve the mechanical properties of the silt layer.

At present, the most advantageous method of the sludge modification is the chemical curing method [2]. The principle of chemical curing method is to modify the sludge by the physical and chemical reaction between the curing agent, the water and active clay minerals in the sludge, which is a relatively mature technology. Considering the effect of cement fineness on hydration products, some

*E-mail address: w_sr88@163.com

ISSN: 1791-2377 @ 2021 School of Science, IHU. All rights reserved.

doi:10.25103/jestr.142.06 scholars have used nano-silica and other nano-materials as cement admixtures to enhance the mechanical properties of modified soils [3, 4], but the high cost of nano-materials makes it difficult to apply them on a large scale. In the early 1970 s, the world's first ultra-fine cement was introduced in Japan [5]. In 1993, Reinhardt took the lead in systematically combing the functions and main uses of ultra-fine cement [6]. Ordinary Portland cement has long been the most popular curing material in geotechnical engineering due to the advantages of excellent performance and low price. However, in the face of the increasingly complex construction environment and scale, as well as the increased emphasis on the project quality and the construction safety, the ordinary Portland cement modified sludge has increasingly highlighted problems such as insufficient strength and low efficiency to meet the actual project requirements.

Compared with the ordinary Portland cement, the ultrafine cement has many advantages such as small particle size, large specific surface area, fast hydration speed, high strength, and good stability [7, 8]. It is a high-performance grouting material composed of the ultra-fine cement and other inorganic ultra-fine particles, which has good permeability, pourability, higher strength, and durability than the organic chemical grouting liquids. Therefore, it can be applied to the foundation reinforcement of various soil environments, various complex foundation reinforcement, the solidification treatment of sand layers, and various complex structural grouting treatments, such as tunnels, 
subways, dams, highways, bridge piers, oil wells, and largescale equipment foundation.

Based on the comparative study on the macro and micro properties of the ultra-fine cement and ordinary Portland cement modified sludge, we found that the performance of the ultra-fine cement modified sludge was far superior to that of the ordinary Portland cement modified sludge. However, the market price of the ultra-fine cement is relatively expensive, and the cost of the sludge modification using only the ultra-fine cement is relatively high.

Aiming to study the effect of the ultra-fine cement content on the mechanical properties and microstructure of the modified sludge, and explain the impact of the ultra-fine cement on the macro-mechanical properties of the modified sludge from a micro level, it is of important engineering value and research significance to explore new materials and methods to improve the engineering mechanical properties of the modified sludge in practical engineering.

\section{State of the art}

To improve the engineering mechanical properties of the modified sludge, many scholars have conducted lots of researches and achieved many valuable results. For example, Wang et al. found that adding the appropriate amount of fiber can not only improve the strength of the modified sludge, but also reduce the brittleness of the modified sludge [9]. Pu et al. self-made a SEU-2 curing agent and compared the mechanical properties of lime, lime-cement mixture and SEU-2 curing agent modified sludge [10]. Cho et al. conducted a sludge modification study with $\mathrm{NaOH}$ activated ground granulated blast furnace slag (GGBFS) [11]. Wang et al. used activated $\mathrm{MgO}$-fly ash as a sludge curing material [12, 13]. Develioglu and Pulat used lime, thermal power plant fly ash and volcanic slag as curing materials to conduct sludge modification studies [14]. Gu et al. relied on alkaline oxidants to decompose organic matter, thereby improving the strength of the modified sludge $[15,16]$. However, the sludge modification methods reported in the existing reports often have defects such as insufficient strength, or complicated process, or high cost, which are difficult to apply in practical engineering [17-20].

Currently, the excellent performance of the ultra-fine cement is being used as a soil curing agent for the soil modification experimental research. For example, Mollamahmutoğlu and Avci investigated the effectiveness of slag-based ultra-fine cement in modifying clayey soils under two different curing conditions [21, 22]. Zheng et al. studied the impact of the ultra-fine cement on the early compressive strength of stabilized soft soils [23]. However, the research on soil modification with ultra-fine cement as soil curing agent is still in the initial stage, and there are few relevant results. In particular, the research on the modification of sludge by the ultra-fine cement is nearly blank, and the influence of ultra-fine cement on the modification effect and microstructure of sludge is still unclear.

Some scholars have done the research on soft soil and sludge modification. Ghadir and Ranjbar compared the mechanical performance of clayey soil stabilization using volcanic ash based geopolymer and ordinary Portland cement [24]. Jamsawang et al. assessed the effectiveness of the bagasse ash as an admixture to improve the unconfined compressive strength and microstructural properties of the soft clay. Ordinary Portland cement is partially replaced with the bagasse ash and mixed with soft clay to generate the admixed soft clay [25]. And some related researches [26-29]. The influence of the ultra-fine cement content on the mechanical properties and microstructure of the modified sludge was investigated in this study by fixing the total cement admixture at $20 \%$ and making the ultra-fine cement gradually replace ordinary Portland cement in a $5 \%$ gradient. It is hoped that the research results will provide the theoretical support and reference for the practical engineering application and further research of the ultra-fine cement in sludge modification.

The rest of this study is organized as follows. Section 3 describes the materials and test procedures. Section 4 gives the experimental results and discussion, and finally, the conclusions are summarized in Section 5.

\section{Methodology}

\subsection{Test material}

\subsubsection{The sludge soil}

The sludge soil sample for the test was taken from a foundation pit in Fuzhou City, China. In its natural state, the sludge was dark gray and saturated with flow plasticity. The basic physical properties of the soil samples are shown in Table 1. According to the Unified Soil Classification System (USCS), the sludge belongs to organic matter high liquid limit silt (MHO). The microstructure of the sludge is shown in Fig. 1. The sludge soil body is mainly composed of flake mineral aggregates occluded and stacked, with loose structure and well-developed pores. The particle size distribution of the test materials shown in Fig. 2 was obtained by a laser particle size distribution meter. The contents of clay, powder and sand particles in the sludge were $22.5 \%, 76.2 \%$ and $1.3 \%$, respectively. The results of X-ray fluorescence spectroscopy (XRF) analysis of the sludge are shown in Table 2, which shows that the main chemical compositions of the sludge used in the test are $\mathrm{SiO}_{2}$, $\mathrm{Al}_{2} \mathrm{O}_{3}$ and $\mathrm{Fe}_{2} \mathrm{O}_{3}$.

Table 1. The basic physical properties of the sludge.

\begin{tabular}{c|c}
\hline Natural water content, $\omega_{0}(\%)$ & 62.5 \\
\hline Density, $\gamma\left(\mathrm{kN} \cdot \mathrm{m}^{-3}\right)$ & 16.02 \\
\hline Specific gravity, $G_{\mathrm{S}}$ & 2.62 \\
\hline Liquid limit*, $\omega_{\mathrm{L}}(\%)$ & 58.4 \\
\hline Plastic limit, $\omega_{\mathrm{P}}(\%)$ & 38.5 \\
\hline Plasticity index, $I_{\mathrm{P}}$ & 19.9 \\
\hline Natural void ratio, $e_{0}$ & 1.685 \\
\hline Organic matter**, $\omega_{\mathrm{u}}(\%)$ & 8.51 \\
\hline $\mathrm{pH}$ & 7.16 \\
\hline
\end{tabular}

Note: $* 17 \mathrm{~mm}$; ** Burning method (burning at $900{ }^{\circ} \mathrm{C}$ for $5 \mathrm{~h}$ ).

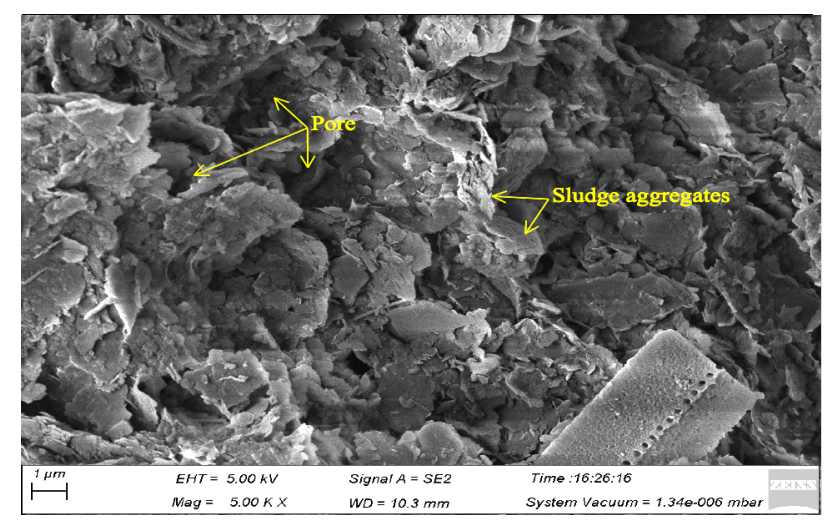

Fig. 1. The microstructure of the sludge. 


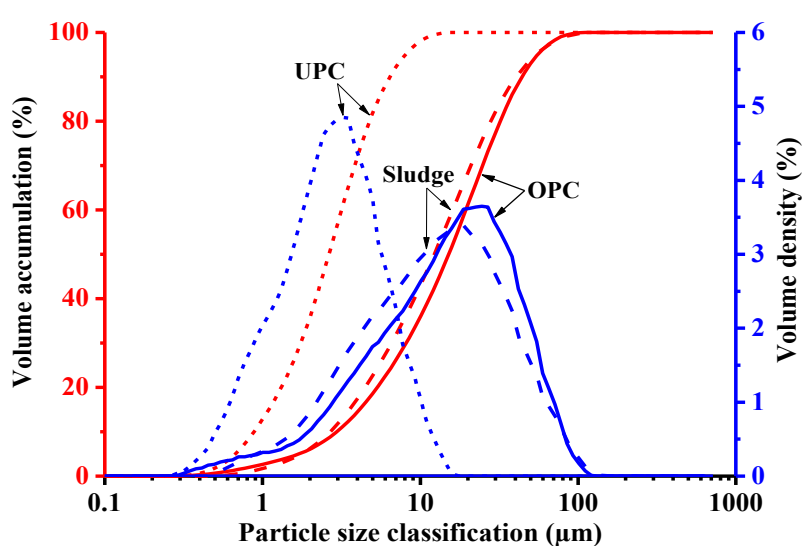

Fig. 2. The particle size distribution of the test materials.

Table 2. The Main chemical compositions of the test materials.

\begin{tabular}{c|c|c|c|c|c|c}
\hline \multirow{2}{*}{ Materials } & \multicolumn{7}{|c}{ Chemical composition (\%) } \\
\cline { 2 - 7 } & $\mathbf{S i O}_{\mathbf{2}}$ & $\mathbf{A l}_{\mathbf{2}} \mathbf{O}_{\mathbf{3}}$ & $\mathbf{F e}_{\mathbf{2}} \mathbf{O}_{\mathbf{3}}$ & $\mathbf{C a O}$ & $\mathbf{M g O}$ & $\mathbf{S O}_{\mathbf{3}}$ \\
\hline Sludge & 60.47 & 23.66 & 6.06 & 0.65 & 1.41 & 1.95 \\
OPC & 19.41 & 6.49 & 3.4 & 59.49 & 4.05 & 4.33 \\
UPC & 22.04 & 9.05 & 3.87 & 53.96 & 3.52 & 4.87 \\
\hline
\end{tabular}

\subsubsection{Curing materials}

Two types of cements were used as sludge curing materials, namely Panglongshan ultra-fine Portland cement (UPC) produced in Jinan, China, and Jiangu P.O 42.5 ordinary Portland cement (OPC) produced in Jiaozuo, China. The particle size distribution and main chemical composition of the test cements are shown in Fig. 2 and Table 2, respectively. And the main physical and mechanical properties of the cements are shown in Table 3. It can be seen from Table 2 that the main chemical compositions of both cements are $\mathrm{CaO}, \mathrm{SiO}_{2}$ and $\mathrm{Al}_{2} \mathrm{O}_{3}$.

Table 3. The main physical and mechanical properties of the cements.

\begin{tabular}{c|c|c|c}
\hline \multicolumn{2}{c|}{ Cement } & OPC & UPC \\
\hline \multicolumn{2}{c|}{ Standard consistency (\%) } & 24.6 & 39.9 \\
\hline \multicolumn{2}{c}{ Specific surface area $\left(\mathrm{m}^{2} / \mathrm{kg}\right)$} & 357 & 1180 \\
\hline \multicolumn{2}{c}{ Soundness } & Qualified & Qualified \\
\hline \multirow{2}{*}{ Setting time (min) } & Initial setting & 165 & 97 \\
\cline { 2 - 4 } & Final setting & 257 & 121 \\
\hline \multirow{2}{*}{ Flexural strength (MPa) } & $3 \mathrm{~d}$ & 5.6 & 7.1 \\
\cline { 2 - 4 } & $28 \mathrm{~d}$ & 8.5 & 9.9 \\
\hline $\begin{array}{c}\text { Compressive strength } \\
(\mathrm{MPa})\end{array}$ & $3 \mathrm{~d}$ & 28.9 & 49.7 \\
\cline { 2 - 4 } & $28 \mathrm{~d}$ & 51.7 & 87.1 \\
\hline
\end{tabular}

\subsection{Test procedures}

\subsubsection{Test scheme}

Referring to the cement mixing pile construction design plan of the sludge sampling foundation pit project, the design cement content is $20 \%$, the water-cement ratio is 0.8 , and the longest curing time is $28 \mathrm{~d}$. The test was carried out to study the sludge modification by gradually replacing ordinary Portland cement with the ultra-fine cement at a gradient of $5 \%$. The specific test scheme is shown in Table 4 , where the cement content is the ratio of the weight of cement to the weight of sludge wet soil in the natural water content state.

Table 4. The specific scheme of the test.

\begin{tabular}{c|c|c|c}
\hline Specimen & \multicolumn{2}{|c|}{ Cement content (\%) } & \multirow{2}{*}{ Curing time (d) } \\
\cline { 2 - 3 } number & OPC & UPC & \\
\hline O20-xd & 20 & 0 & $1,3,7,14,28$, \\
U5O15-xd & 15 & 5 & $1,3,7,14,28$, \\
U10O10-xd & 10 & 10 & $1,3,7,14,28$, \\
U15O5-xd & 5 & 15 & $1,3,7,14,28$, \\
U20-xd & 0 & 20 & $1,3,7,14,28$, \\
\hline
\end{tabular}

Note: The $\mathrm{x}$ of the specimen number represents the curing time.

\subsubsection{Specimen preparation}

Before specimen preparation, the sludge was made into powder through three steps of air-drying, crushing and passing through $0.5 \mathrm{~mm}$ standard sieve. Then the water content of the sludge powder was measured and sealed in a self-sealing plastic bag for storage. Only one kind of cylindrical specimen with the size of $\Phi 3.91 \mathrm{~cm} \times 8.00 \mathrm{~cm}$ was used in this test, and the specimen-making mold used was a steel three-flap mold with the internal size of $\Phi 3.91$ $\mathrm{cm} \times 8.00 \mathrm{~cm}$.

The specimen preparation process is divided into five steps. Firstly, the sludge powder, cement and water are weighed according to the proportions designed in the test scheme. The water is composed of two parts, one part is the mass of water required to prepare the dry sludge powder into the natural water content state sludge, and the other part is the mass of water required to configure the cement slurry. Secondly, mix the sludge powder and cement evenly, then add the weighed water and mix evenly using an electric mixer. Thirdly, the uniformly mixed modified sludge mixture is loaded into the assembled three-flap mold in 5-8 layers, and each layer is manually vibrated before the next layer is loaded, until the last layer is vibrated and the surface is scraped smooth. Fourthly, cover the upper surface of the specimen with cling film and a small glass sheet, and mark it well. Let it stand in the room for $24 \mathrm{~h}$ and then demold and weigh. Finally, the surface of the demolded specimen is sprinkled with water and moistened, then wrapped and sealed with plastic cling film, numbered and recorded, and placed indoors at room temperature $\left(25-30^{\circ} \mathrm{C}\right)$ for maintenance until the set curing time for mechanical properties and microstructure test.

\subsubsection{Test methods}

The unconfined compressive strength (UCS) test and unconsolidated undrained (UU) triaxial shear test were carried out after the specimens were cured to the set curing time. The unconfined compressive strength test was conducted using a WDW-50kN electronic universal testing machine with a range of $50 \mathrm{kN}$ and an accuracy of $1 \mathrm{~N}$. The axial loading rate was set at $0.1 \mathrm{kN} / \mathrm{s}$. Two parallel specimens were measured for each group of specimens and the average value was taken as the representative result. The UU triaxial shear test was adopted by model TSZ-3A full automatic strain controlled triaxial test apparatus. The sequence of confining pressure load $\sigma_{3}$ for each group of specimens was set as $100 \mathrm{kPa}, 200 \mathrm{kPa}$ and $300 \mathrm{kPa}$. Two parallel specimens were measured under each level of confining pressure load, and the average value was obtained as the representative result.

After the end of the unconfined compressive strength test, the internal fragments of partially damaged specimens were selected and dehydrated for microscopic analysis tests such as mercury intrusion porosimetry and scanning electron microscopy. The mercury intrusion porosimetry test adopts the AutoPore Iv 9510 fully automatic mercury porosimeter from the United States, and the specimen needs to be processed into a cubic block with a side length of about 5 $\mathrm{mm}$ before the test. The scanning electron microscopy test was conducted using a German Merlin Compact type scanning electron microscope, and the observation specimen should be ensured to have a fresh fracture section during observation. 


\section{Results analysis and discussions}

\subsection{Mechanical properties of modified sludge}

\subsubsection{Strength characteristics}

Keeping the total cement content at $20 \%$ and making the ultra-fine cement gradually replace ordinary Portland cement with a $5 \%$ gradient. The unconfined compressive strength $q_{\mathrm{u}}$ of the modified sludge is shown in Fig. 3.

As can be seen from Fig. 3, the unconfined compressive strength of the modified sludge exhibits a fast and then slow power function growth law with the extension of the curing time. Chiu et al. pointed out that the strength growth of cement modified sludge is the result of the development of soil structure during the cementation process of cement hydration products [30]. After contacting with the pore water in the sludge, the cement quickly undergoes hydration reaction and generates a large amount of cementation products, which is macroscopically manifested as a rapid increase in the strength of the modified sludge. With the extension of the curing time, the continuous consumption of cement and the formation of soil structure lead to a decrease in the rate of continued generation of cementitious products, which is macroscopically manifested by a slowdown in the strength growth of the modified sludge. Therefore, the strength of the modified sludge integrally exhibits a fast and then slow growth law with the extension of the curing time.

In addition, Fig. 3 also shows that the unconfined compressive strength of the modified sludge increases approximately linearly with the increase of the ultra-fine cement content for all curing time. This phenomenon indicates that the addition of ultra-fine cement changes the hydration reaction rate of cement and promotes the formation of cementitious products in the modified sludge, and this promotion effect increases with the increase of the ultra-fine cement content.

To evaluate the ability of different ultra-fine cement contents to improve the strength of the modified sludge, the strength growth rate $R_{\mathrm{sg}}$ was defined. The strength growth rate refers to the ratio of the increment of the unconfined compressive strength of the modified sludge relative to the unconfined compressive strength of $\mathrm{O} 20$ specimens of the same curing time to the unconfined compressive strength of O20 specimens, the results of which are shown in Fig. 4, where the $\mathrm{O} 20$ specimens are the modified sludge specimens without the addition of ultra-fine cement.

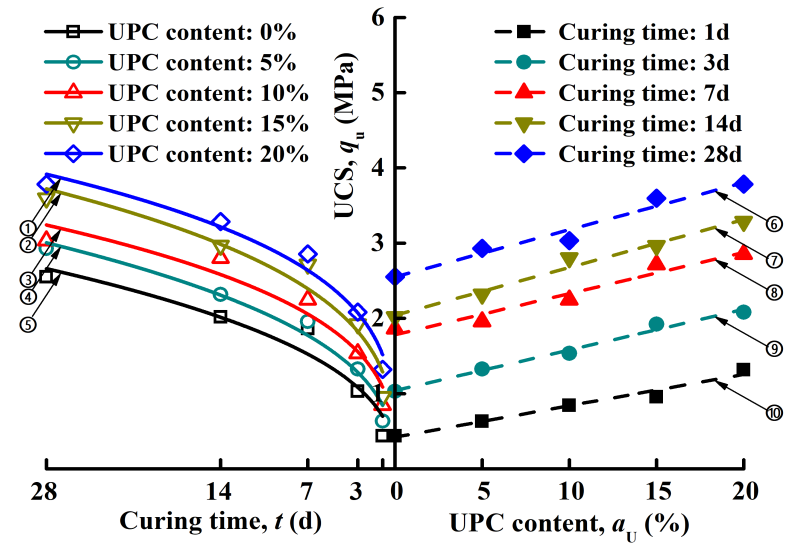

\begin{tabular}{|c|c|}
\hline $\begin{array}{l}\text { (1) } q_{\mathrm{u}}=0.698 t^{0.402}, \mathrm{R}^{2}=0.91 \\
\text { (2) } q_{\mathrm{u}}=0.846 t^{0.38}, \mathrm{R}^{2}=0.96 \\
\text { (3) } q_{\mathrm{u}}=1.087 t^{0.328}, \mathrm{R}^{2}=\mathbf{0 . 9 2} \\
\text { (4) } q_{\mathrm{u}}=1.289 t^{0.318}, \mathrm{R}^{2}=\mathbf{0 . 9 2} \\
\text { () } q_{\mathrm{u}}=1.517 t^{0.285}, \mathrm{R}^{2}=\mathbf{0 . 9 6}\end{array}$ & $\begin{array}{l}\text { () } q_{\mathrm{u}}=\mathbf{0 . 0 4 2} a_{\mathrm{U}}+\mathbf{0 . 4 2 3}, \mathrm{R}^{2}=\mathbf{0 . 9 6} \\
\text { () } q_{\mathrm{u}}=\mathbf{0 . 0 5 4} a_{\mathrm{U}}+\mathbf{1 . 0 4 1}, \mathrm{R}^{2}=\mathbf{0 . 9 8} \\
\text { () } q_{\mathrm{u}}=\mathbf{0 . 0 5 5} a_{\mathrm{U}}+\mathbf{1 . 7 8 2}, \mathrm{R}^{2}=\mathbf{0 . 9 4} \\
\text { () } q_{\mathrm{u}}=\mathbf{0 . 0 6 4} a_{\mathrm{U}}+\mathbf{2 . 0 4 2}, \mathrm{R}^{2}=\mathbf{0 . 9 7} \\
\text { (1) } q_{\mathrm{u}}=\mathbf{0 . 0 6 3} a_{\mathrm{U}}+\mathbf{2 . 5 5 3}, \mathrm{R}^{2}=\mathbf{0 . 9 5}\end{array}$ \\
\hline
\end{tabular}

Fig. 3. UCS of modified sludge with curing time and UPC content.
It can be found that the strength growth rate of the modified sludge at different curing time changes with the change of the ultra-fine cement content in a similar pattern, all of them show an increase with the increase of the ultrafine cement content in a roughly positive proportional function, which can be expressed by Eq. (1). This phenomenon indicates that the addition of ultra-fine cement increases the specific surface area of the cement, which increases the contact area between the cement particles and the pore water in the modified sludge, enhances the rate of cement hydration reaction and the adequacy of the reaction, and thereby improves the strength of the modified sludge.

$R_{\mathrm{sg}}=k a_{\mathrm{U}}$

where, $k$ is the slope of the fitted straight line of strength growth rate, and its value characterizes the rate of increase of strength growth rate with the increase of ultra-fine cement content. $a_{\mathrm{U}}$ is the content of the UPC.

The greater the value of $k$, the greater the rate of the strength growth rate with the increase of the ultra-fine cement content. On the contrary, the smaller the value of $k$, the smaller the rate of the strength growth rate with the increase of the ultra-fine cement content. What is obvious from Fig. 4 is that the value of $k$ is related to the curing time. The value of $k$ decreases with the extension of the curing time. Taking $7 \mathrm{~d}$ as the node, the value of $\mathrm{k}$ before $7 \mathrm{~d}$ is relatively large and decreases very significantly with the extension of the curing time. The value of $\mathrm{k}$ after $7 \mathrm{~d}$ is relatively small and decreases insignificantly with the extension of the curing time. The strength growth rates of modified sludge with the same ultra-fine cement content were relatively close at the curing time of $7 \mathrm{~d}, 14 \mathrm{~d}$ and $28 \mathrm{~d}$.

The changes in strength growth rates and value of $k$ indicated that the addition of ultra-fine cement not only improved the strength of the modified sludge as a whole, but also had a very significant influence on the early strength of the modified sludge. The reason is that the ultra-fine cement particle size is small, large surface area, high activity, the addition of ultra-fine cement makes the cement curing agent particle size becomes smaller, the specific surface area becomes larger, while the activity is enhanced.

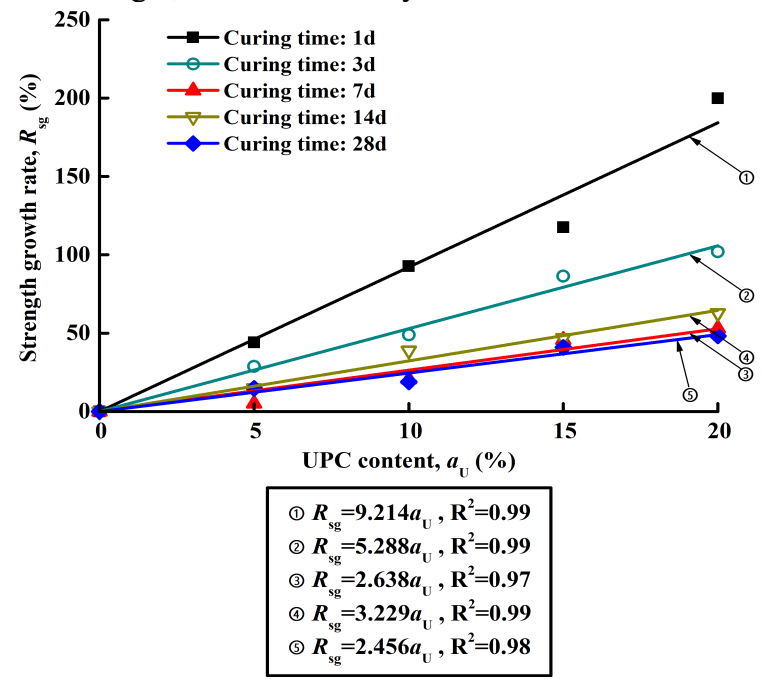

Fig. 4. Strength growth rate of modified sludge with UPC content.

In the process of sludge modification, the addition of ultra-fine cement makes the contact area between the cement and the pore water increase significantly in the early stage, and the rate of cement hydration reaction increases 
significantly, which results in a substantial increase in the strength of the modified sludge. The consumption of the continuous hydration reaction of the ultra-fine cement and the formation of the modified sludge soil structure with the extension of the curing time lead to a gradual decrease of the cement hydration reaction rate in the modified sludge. Eventually, the rate of cement hydration reaction in the modified sludge forms some roughly stable multiplicative relationship with the rate of cement hydration reaction in the O20 specimen.

\subsubsection{Strength prediction models}

Fig. 3 shows that the unconfined compressive strength $q_{\mathrm{u}}$ of the modified sludge is related to the curing time $t$ and the ultra-fine cement content as a power function and a linear function, respectively, which can be expressed by Eqs. (2) and (3), respectively.

$$
q_{\mathrm{u}}=\mathrm{A} t^{\mathrm{B}}
$$

where, A and B are parameters related to the ultra-fine cement content.

$$
q_{\mathrm{u}}=\mathrm{C} a_{\mathrm{U}}+\mathrm{D}
$$

where, $\mathrm{C}$ and $\mathrm{D}$ are the parameters related to the curing time.

Fig. 5 shows that A and B are both linear functions with the ultra-fine cement content, which can be expressed by Eqs. (4) and (5), respectively. Fig. 6 shows that C and D are both exponential functions with the ultra-fine cement content, which can be expressed by Eqs. (6) and (7), respectively.

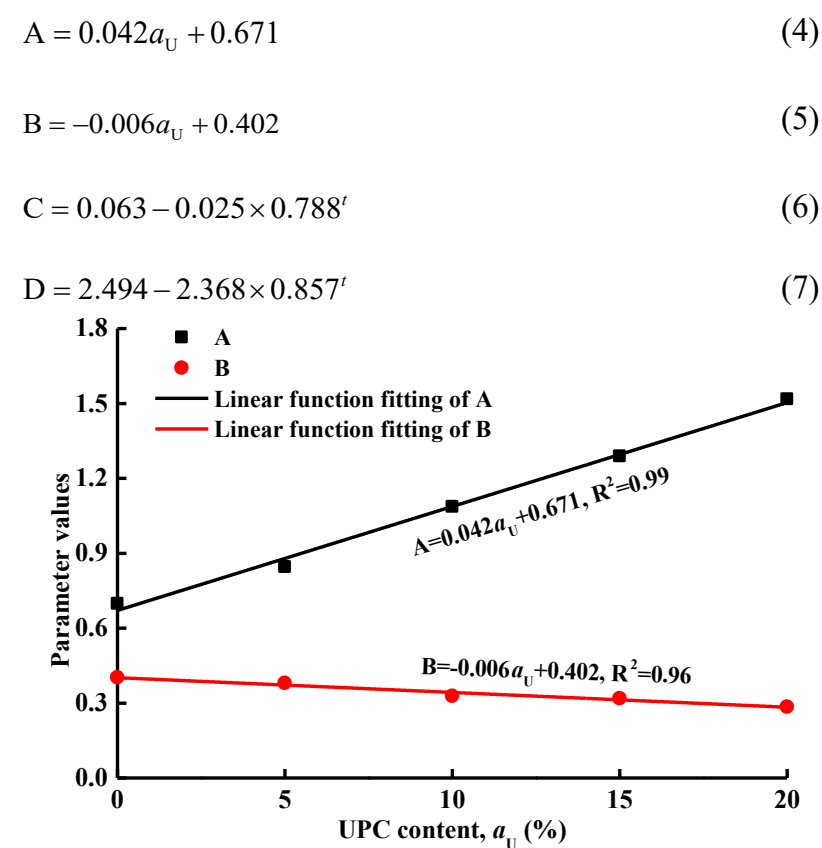

Fig. 5. Parameters A and B versus UPC content.

Combining Eqs. (2), (4), and (5) yields the strength prediction model I shown in Eq. (8), and combining Eqs. (3), (6), and (7) yields the strength prediction model II shown in Eq. (9). Fig. 7 shows the relationship between the solved values of the strength prediction models and the measured values of the unconfined compressive strength.

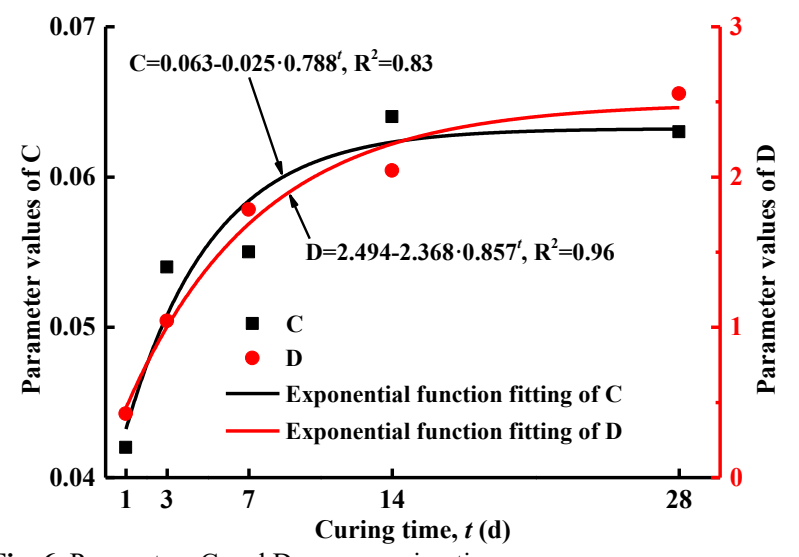

Fig. 6. Parameters $C$ and $D$ versus curing time.

It is found that there is a positive proportional function between the solved values of the strength prediction models I and II and the measured values of the unconfined compressive strength by function fitting, and the proportionality coefficients are close to 1 . This means that both the strength prediction equations can well predict the unconfined compressive strength of modified sludge with different ultra-fine cement contents replacing ordinary Portland cement when the total cement content is $20 \%$, which can provide a reference for practical projects. Among them, the proportionality coefficient and the goodness of fit $\mathrm{R}^{2}$ of the fitting function of model II are both closer to 1 , indicating that the predicted strength of model II is closer to the measured strength than that of model I.

$$
\begin{aligned}
& q_{\mathrm{u}-\mathrm{I}}=\left(0.042 a_{\mathrm{U}}+0.671\right) t^{\left(-0.006 a_{\mathrm{U}}+0.402\right)} \\
& q_{\mathrm{u}-\mathrm{II}}=\left(0.063-0.025 \times 0.788^{t}\right) a_{\mathrm{U}} \\
& -2.368 \times 0.857^{t}+2.494
\end{aligned}
$$

\subsubsection{Stress-strain curves}

The stress-strain curves of the modified sludge obtained from the unconfined compressive strength test are shown in Fig. 8. Analyzing the stress-strain curves, it can be found that: (1) Except for the three groups of specimens O20-1d, U5O15-1d and O20-3d, which exhibit strong plastic characteristics, all the modified sludge specimens exhibit significant brittleness characteristics. The stress-strain curves exhibit strain softening and there is an obvious peak stress, and the specimens show a brittle failure mode. (2) With the increase of the ultra-fine cement content and the extension of the curing time, the plastic deformation capacity of the modified sludge specimens gradually decreases and the brittle characteristics gradually increase.

The reason for the above phenomenon is that the addition of ultra-fine cement improves the activity of the cement and increases the specific surface area of the cement. During the process of sludge modification, the addition of ultra-fine cement enhances the rate of cement hydration reaction, the hydration products are generated faster, and more hydration products are generated in the modified sludge at the same curing time. The hydration products cement the soil particles to form the soil skeleton. The increase of the ultra-fine cement content makes the formation of soil skeleton of the modified sludge faster, with higher skeleton strength and better overall structural properties. Macroscopically, the modified sludge can better resist external forces as a whole within the same curing time, which is reflected in the weakening of plastic densification 
and the increase of brittle characteristics of the specimens with the increase of the ultra-fine cement content and the extension of the curing time.

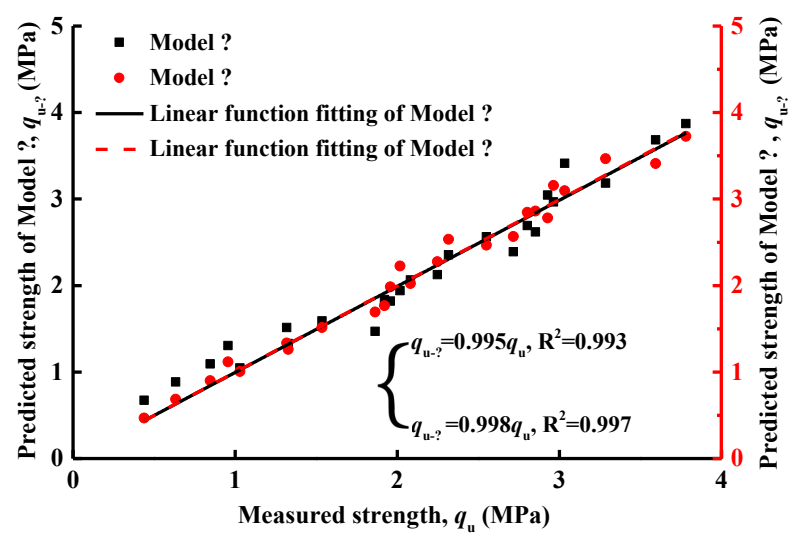

Fig. 7. Model predicted strength versus measured strength.

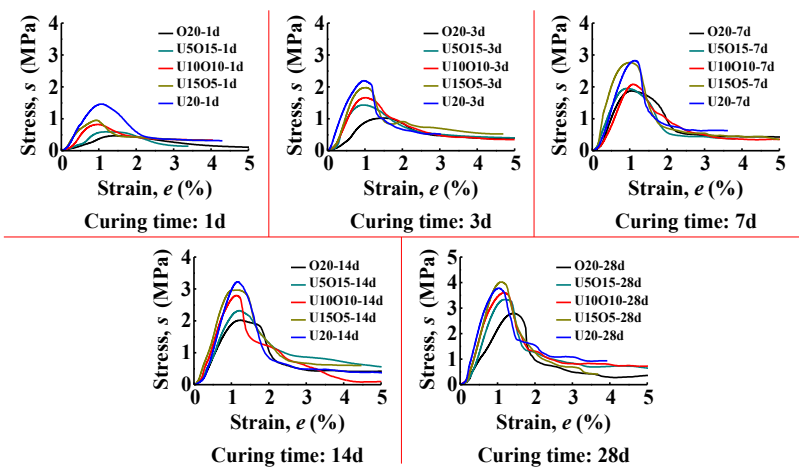

Fig. 8. The stress-strain curves of the modified sludge.

\subsubsection{Deformation characteristics of the modified sludge} As an important part of the engineering mechanical properties of soils, deformation characteristics have an important impact on practical engineering. The deformation characteristics of the modified sludge were analyzed by investigating the failure strain $\varepsilon_{f}$ and the deformation modulus $E_{50}$ of the modified sludge in the unconfined compressive strength test. $\varepsilon_{f}$ reflects the deformation capacity of the material. The larger the $\varepsilon_{f}$, the greater the toughness and the stronger the deformation capacity of the material. Conversely, the smaller the $\varepsilon_{f}$, the greater the brittleness and the weaker the deformation ability of the material. $E_{50}$ is the cut line modulus corresponding to the compressive strain of $0.5 \varepsilon_{f}$ on the stress-strain curves, which reflects the capacity of the deformation resistance of the material. The larger the $E_{50}$, the stronger the deformation resistance of the material. On the contrary, the smaller the $E_{50}$, the weaker the deformation resistance of the material.

Fig. 9 shows the relationship between the deformation modulus $E_{50}$, the failure strain $\varepsilon_{f}$ and the unconfined compressive strength $q_{\mathrm{u}}$ of the modified sludge. It is observed that the change of the deformation modulus $E_{50}$ of the modified sludge has a good agreement with the development of the unconfined compressive strength $q_{\mathrm{u}} . E_{50}$ increases proportionally with the increase of the unconfined compressive strength $q_{\mathrm{u}}$. The ratio of $E_{50}$ to $q_{\mathrm{u}}$ varied between 62.61 and 162.20. A functional expression $E_{50}=98.18 q_{\mathrm{u}}$ for $E_{50}$ with respect to $q_{\mathrm{u}}$ was obtained by linear fitting, and the goodness of fit $R^{2}=0.95$ indicates that the expression can better describe the relationship between the deformation modulus $E_{50}$ of the modified sludge and the unconfined compressive strength $q_{\mathrm{u}}$. In addition, some studies have pointed out that the failure strain $\varepsilon_{f}$ of cement modified soils decreases with the increase of the unconfined compressive strength $q_{\mathrm{u}}$, and shows a power function or exponential function change relationship [31]. However, it is difficult to establish a mathematical model expressing the relationship between $\varepsilon_{f}$ and $q_{\mathrm{u}}$ for the experimental data obtained in this study. Nevertheless, it can still be found that the distribution of the failure strain $\varepsilon_{f}$ of the modified sludge is more concentrated, which is mainly distributed between $0.8 \%$ and $1.5 \%$, and shows a tendency to decrease with the increase of the unconfined compressive strength $q_{\mathrm{u}}$.

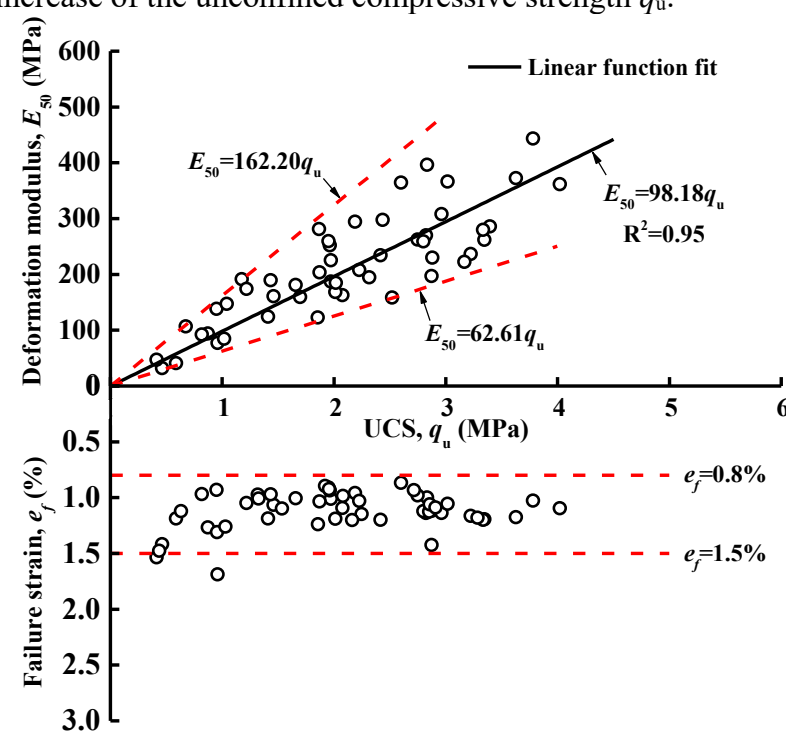

Fig. 9. The relationship among deformation modulus, failure strain and the UCS.

Fig. 10 shows the relationship between the failure strain $\varepsilon_{f}$, the deformation modulus $E_{50}$ and the ultra-fine cement content of the modified sludge. Fig. 10 displays that the failure strain $\varepsilon_{f}$ of the modified sludge shows a decreasing trend overall with the increase of the ultra-fine cement content, which indicates that the toughness of the modified sludge decreases and the brittleness increases with the increase of the ultra-fine cement content. The deformation modulus $E_{50}$ of the modified sludge gradually increased with the increase of the ultra-fine cement content, which indicates that the capacity of the deformation resistance of the modified sludge was enhanced by the increase of the ultrafine cement content.

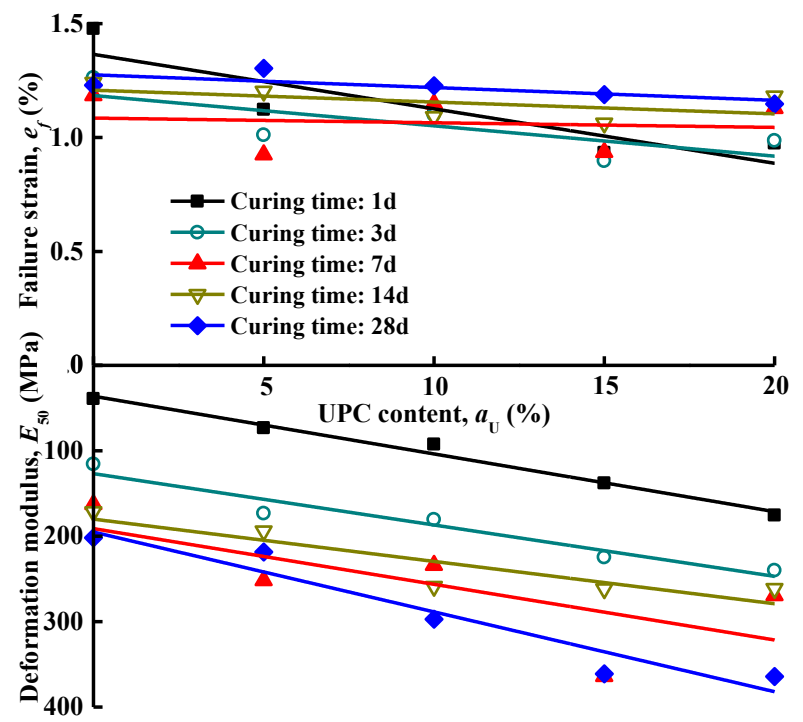

Fig. 10. The relationship among failure strain, deformation modulus and the UPC content. 


\subsubsection{Cohesion and internal friction angle}

The shear strength of soil has an important influence and significance on engineering activities. The Coulomb shear strength equation $\tau=c+\sigma \tan \varphi$ indicates that the shear strength of soil consists of cohesion $c$ and internal friction angle $\varphi$. In the process of sludge modification, the cohesion $c$ and the internal friction angle $\varphi$ of the modified sludge are inevitably changed along with the occurrence of a series of physical and chemical reactions and the generation of chemical products. In this study, the changes of the shear strength index cohesion $c_{\mathrm{u}}$ and internal friction angle $\varphi_{\mathrm{u}}$ of the modified sludge were investigated by UU triaxial shear test.

After the UU triaxial shear test, the Mohr circle and Mohr line were plotted on the $\tau$ - $\sigma$ coordinate plane based on the test results. The intercept in vertical coordinates and horizontal inclination of the Mohr line are the cohesion $c_{\mathrm{u}}$ and the internal friction angle $\varphi_{\mathrm{u}}$ of the modified sludge specimen, respectively. Take the O20-1d specimen as an example. The Mohr circle and the Mohr line are shown in Fig. 11. The cohesion $c_{\mathrm{u}}$ and the internal friction angle $\varphi_{\mathrm{u}}$ of the $020-1 \mathrm{~d}$ specimen are $102.3 \mathrm{kPa}$ and $14.7^{\circ}$, respectively. Calculate the cohesion $c_{\mathrm{u}}$ and the internal friction angle $\varphi_{\mathrm{u}}$ for the other specimens in turn.

The cohesion $c_{\mathrm{u}}$ and the internal friction angle $\varphi_{\mathrm{u}}$ of the modified sludge were plotted as intuitive fitted curves as shown in Figs. 12 and 13, respectively. Fig. 12 shows the relationship between the cohesion $c_{\mathrm{u}}$ of the modified sludge and the curing time and ultra-fine cement content. According to Fig. 12, the cohesion $c_{\mathrm{u}}$ of the modified sludge changes with the curing time and the ultra-fine cement content in the same way as the unconfined compressive strength of the modified sludge, showing a fast and then slow growth with the extension of the curing time, and a approximately linear growth with the increase of the ultrafine cement content. This phenomenon indicates that the change of the cohesion $c_{\mathrm{u}}$ of the modified sludge is closely related to the amount of cement hydration products generated in the modified sludge.

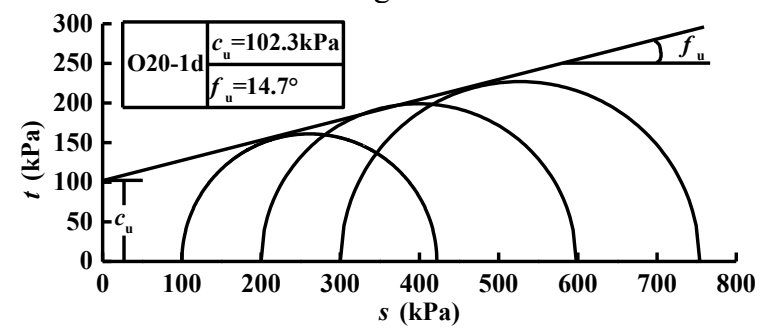

Fig. 11. Mohr circle and Mohr line.

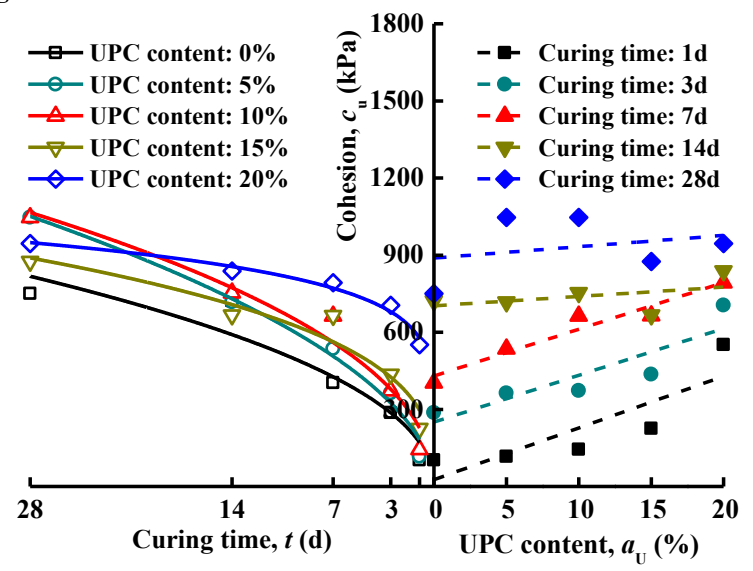

Fig. 12. The cohesion of the modified sludge with the curing time and the UPC content.

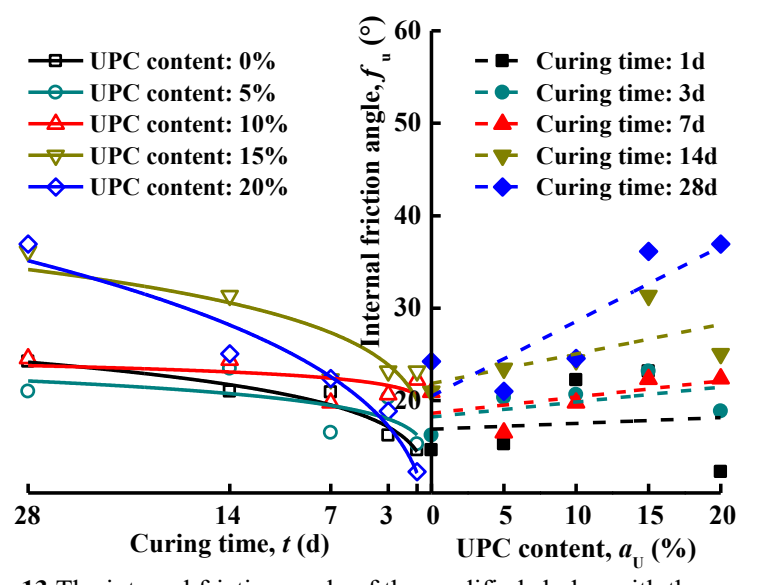

Fig. 13. The internal friction angle of the modified sludge with the curing time and the UPC content.

Fig. 13 shows the relationship between the internal friction angle $\varphi_{\mathrm{u}}$ of the modified sludge and the curing time and ultra-fine cement content. The internal friction angle $\varphi_{\mathrm{u}}$ obtained by the test changes less regularly with the curing time and the ultra-fine cement content. Nevertheless, the curve fitting revealed that on the whole, the internal friction angle $\varphi_{\mathrm{u}}$ of the modified sludge also showed a fast and then slow growth law with the curing time, and increased approximately linearly with the increase of the ultra-fine cement content. The phenomenon demonstrates that not only the cohesion $c_{\mathrm{u}}$ of the modified sludge is related to the amount of cement hydration products generated, but also the internal friction angle $\varphi_{\mathrm{u}}$ of the modified sludge is related to the amount of cement hydration products generated.

\subsection{Microstructure analysis}

\subsubsection{Microstructure of modified sludge}

The microstructure of the modified sludge was observed by scanning electron microscope. The microscopic mechanism of the influence of ultra-fine cement on the mechanical properties of the modified sludge is discussed by analyzing the types, microscopic forms and mode of action of cement hydration products. Fig. 14 shows the scanning electron microscopy images of three groups of different modified sludge specimens at 5000 times magnification.

Fig. 14 shows that the new chemical products generated in the modified sludge of different curing time and cement compositions are all mainly three cement hydration products: flaky $\mathrm{Ca}(\mathrm{OH})_{2}$ crystals, flocculent hydrated calcium silicate (CSH) gels, and pin-rods of calcium alumina (AFt) crystals [29]. The content of $\mathrm{Ca}(\mathrm{OH})_{2}$ is less in the three cement hydration products, and $\mathrm{CSH}$ and AFt are the main sources of the strength of the modified sludge. The above mentioned three cement hydration products interweave with each other to wrap and cement the sludge aggregates during the sludge modification process. The cement hydration products change the connection of the sludge aggregates and fill the pores in the modified sludge, which can make the sludge formed a dense and monolithic structure after modification is the main reason for the improved mechanical properties of the modified sludge. 

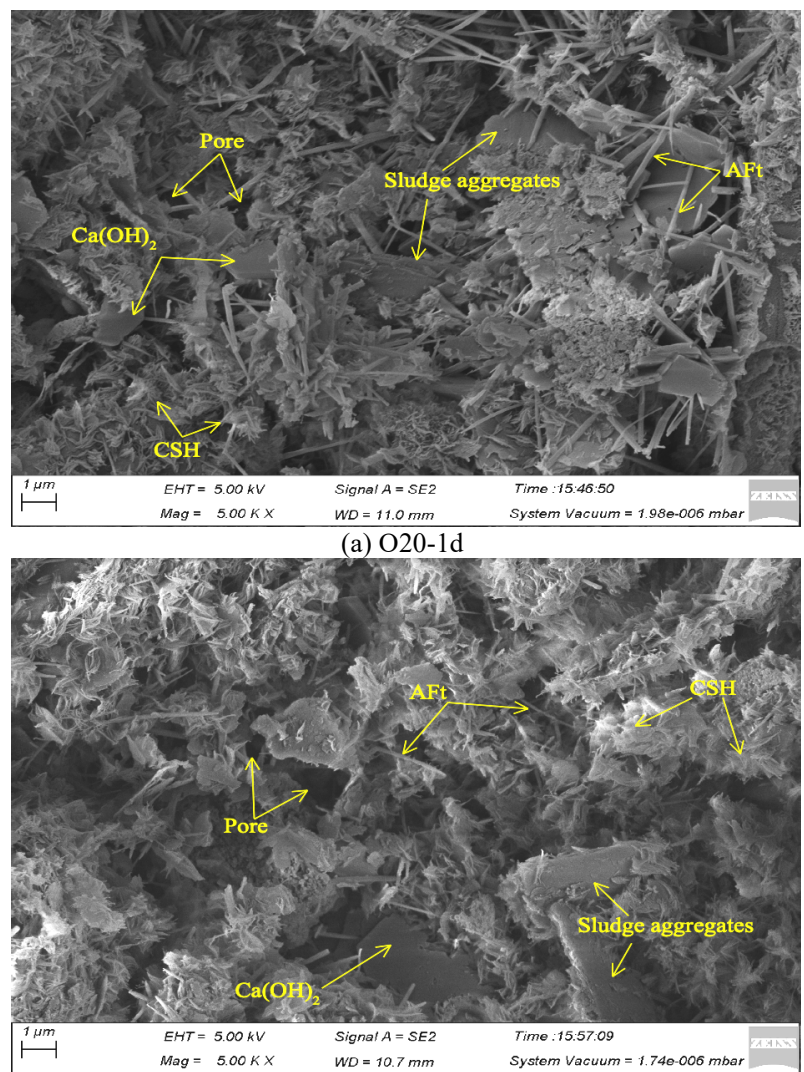

(b) $\mathrm{O} 20-7 \mathrm{~d}$

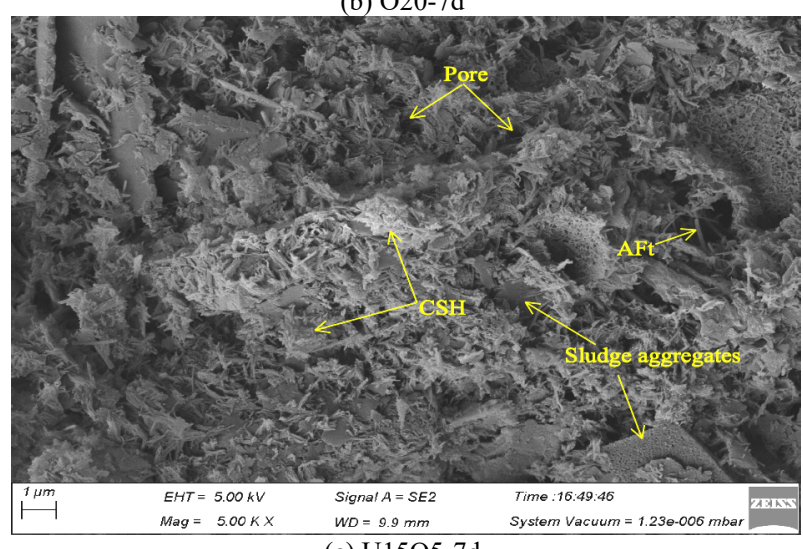

(c) $\mathrm{U} 15 \mathrm{O} 5-7 \mathrm{~d}$

Fig. 14. The microstructure of the modified sludge.

It can be found in comparing Figs. 14(a) and 14(b), the generation of $\mathrm{CSH}$ gel products in the modified sludge increases significantly with the extension of the curing time, the pore content decreases, and the modified sludge soil body becomes more dense. This change has good consistency with the mechanical properties of the modified sludge, indicating that the structural enhancement of the modified sludge is the fundamental reason for the improvement of its mechanical properties.

Similarly, comparing Figs. 14(b) and 14(c), the addition of ultra-fine cement results in more $\mathrm{CSH}$ gel production in the modified sludge for the same curing time, which leads to an obvious reduction of soil pores, a denser soil structure and better integrity in the modified sludge. This is the essential reason why the unconfined compressive strength, brittleness, cohesion and internal friction angle of the modified sludge increase with the increase of the ultra-fine cement content.

\subsubsection{Characteristics of pore structure}

The foregoing microstructural analysis shows that the generation of cement hydration products during the sludge modification process changes the pore structure of the soil. To reveal the relationship between the mechanical properties and the pore structure of the modified sludge, and to explain the influence of the ultra-fine cement on the mechanical properties of the modified sludge from the perspective of the pore structure characteristics, mercury intrusion porosimetry tests were conducted on the sludge and the $7 \mathrm{~d}$ curing time modified sludge. The test results are shown in Table 5 and Fig. 14.

Table 5 shows the porosity, most available pore diameter and average pore diameter of the sludge and modified sludge. The porosity, most available pore diameter and average pore diameter of the modified sludge are much smaller than those of the sludge, indicating that the cement hydration products fill the pores in the soil body while cementing the sludge aggregates during the modification of the sludge. The porosity of the modified sludge was closer and changed less, but it still maintained the trend of decreasing with the increase of the ultra-fine cement content, which indicated that the addition of ultra-fine cement produced more cement hydration products inside the modified sludge specimens and filled more soil pores. In contrast, the most available pore diameter and the average pore diameter of the modified sludge changed more obviously with a larger trend of reduction, which indicates that the main influence of the replacement of ordinary Portland cement by ultra-fine cement on the pore structure of the modified sludge is to reduce the pore diameter.

Table. 5. Porosity, most available pore diameter and average pore diameter of sludge and modified sludge.

\begin{tabular}{c|c|c|c}
\hline Specimen & Porosity & Most available & Average pore \\
\hline Sludge & 61.47 & 0.5166 & 0.0994 \\
O25-7d & 55.82 & 0.3490 & 0.0530 \\
U5O15-7d & 55.17 & 0.2831 & 0.0515 \\
U10O10-7d & 55.45 & 0.2703 & 0.0510 \\
U15O5-7d & 55.00 & 0.2264 & 0.0487 \\
U20-7d & 54.11 & 0.1831 & 0.0473 \\
\hline
\end{tabular}

Fig. 15 illustrates the percentage of pore diameter interval distribution of the sludge and the modified sludge. The pore diameter of all specimens is mainly distributed between $0.01-1 \mu \mathrm{m}$, while the main pore diameter changes of the modified sludge are also in the range of 0.01-1 $\mu \mathrm{m}$. The percentage of pores with a pore diameter between $0.1-1$ $\mu \mathrm{m}$ was greatly reduced and the percentage of pores with a pore diameter between $0.01-0.1 \mu \mathrm{m}$ was significantly increased after the sludge modification. The percentage of pores with a pore diameter between $0.1-1 \mu \mathrm{m}$ decreased, the percentage of pores with a pore diameter between 0.01-0.1 $\mu \mathrm{m}$ increased, and the percentage of pores within the other pore diameter intervals did not change significantly with the increase of the ultra-fine cement content in the modified sludge. The above phenomenon shows that the cement hydration products mainly fill the pores with a pore diameter of $0.1-1 \mu \mathrm{m}$ during the process of sludge modification, and also shows that the increase of the ultra-fine cement content makes more pores with a pore diameter of $0.1-1 \mu \mathrm{m}$ transformed into pores with a pore diameter of 0.01-0.1 $\mu \mathrm{m}$, which supports that the main influence of the ultra-fine cement on the pore structure of the sludge is to reduce the pore diameter. 


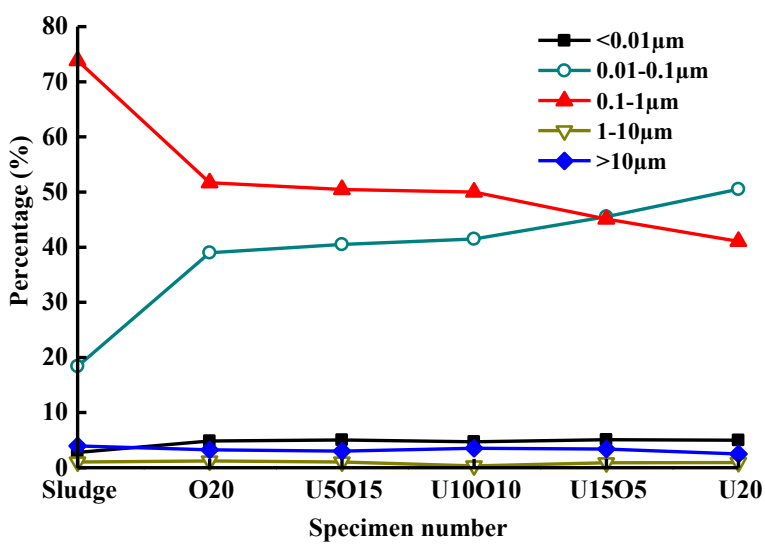

Fig. 15. The percentage of pore diameter interval distribution of the sludge and the modified sludge.

The influence of the ultra-fine cement on the pore structure of the modified sludge is mainly manifested in the influence on the pore size. Relating the pore structure characteristics to the mechanical properties of the modified sludge, the results show that the cement hydration reaction in the modified sludge is accelerated and the generation of cement hydration products increases with the increase of the ultra-fine cement content. These cement hydration products can fill more soil body pores while cementing soil particles, which is macroscopically manifested by the enhancement of unconfined compressive strength, brittleness, cohesion and internal friction angle of the modified sludge.

\section{Conclusions}

The influence of ultra-fine cement content on the mechanical properties and microstructure of modified sludge were investigated by setting the total cement content at $20 \%$ and making the ultra-fine cement gradually replace ordinary Portland cement with a gradient of $5 \%$, and the mechanism of the ultra-fine cement affecting the mechanical properties of the modified sludge was analysed from the microscopic level. The main conclusions are as following:

(1) The content of the ultra-fine cement has an important effect on the mechanical properties of the modified sludge. The unconfined compressive strength, cohesion and internal friction angle of the modified sludge increased linearly with the increase of the ultra-fine cement content. The higher the ultra-fine cement content, the lower the failure strain of the modified sludge, the higher the deformation modulus, and the higher the brittleness and deformation resistance.

(2) Two prediction models for the unconfined compressive strength of modified sludge were proposed. The strength growth rate was defined. According to the relationship between the strength growth rate and the ultrafine cement content, it was found that the addition of ultrafine cement enhanced the rate and adequacy of the cement hydration reaction, which not only improved the strength of the modified sludge as a whole, but also had a significant influence on the early strength of the modified sludge.

(3) Microstructural analysis shows that the ultra-fine cement content has a large effect on the amount of CSH gel production. The higher the ultra-fine cement content, the higher the amount of CSH gel generation. The essential reason for the influence of ultra-fine cement on the mechanical properties of modified sludge is the reduction of microscopic pore size, the improvement of denseness, the enhancement of monolithic and structural properties of the modified sludge soil body.

Although the influence of ultra-fine cement content on the mechanical properties and microstructure of modified sludge was investigated by fixing the total cement admixture at $20 \%$ and making the ultra-fine cement gradually replace ordinary Portland cement with a gradient of $5 \%$, there is still a gap with practical engineering applications. Some model tests similar to the actual engineering applications and field tests should be conducted in future studies to make up for the inadequacy of indoor sludge modification tests.

\section{Acknowledgements}

This work was financially supported by the National Natural Science Foundation of China (51774112), and the Fundamental Research Funds for the Universities of Henan Province (NSFRF200202).

This is an Open Access article distributed under the terms of the Creative Commons Attribution License.

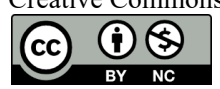

\section{References}

1. Lang, L., Chen, B., Li, N., "Utilization of lime/carbide slag-activated ground granulated blast-furnace slag for dredged sludge stabilization". Marine Georesources and Geotechnology, 2019, pp. $1-11$.

2. Peng, C., Tian, Z. K., Tan, Y. Q., Long, H., "Experimental study on the effect of cement-lime double admixture on dewatering and strength of sludge". IOP Conference Series Earth and Environmental Science, 304, 2019, pp. 052073.

3. Choobbasti, A. J., Kutanaei, S. S., "Microstructure characteristics of cement-stabilized sandy soil using nanosilica". Journal of Rock Mechanics and Geotechnical Engineering, 9(5), 2017, pp. 981-988.

4. Yao, K., Wang, W., Li, N., Zhang, C., Wang, L. X., "Investigation on strength and microstructure characteristics of nano-MgO admixed with cemented soft soil". Construction and Building Materials, 206, 2019, pp. 160-168.

5. Bensted, J., "Microfine cements". World cement, 23(12), 1992, pp. 45-47.

6. Reinhardt, H. W., "Ultra-fine cements for special applications". Advanced Cement Based Materials, 1(2), 1993, pp. 106-107.
7. You, Q., Wang, H., Dai, C. L., Liu, Y. F., Fang, J. C., Zhao, G., Zhao, M. W., Wang, K., "Case study on in-depth blocking for thermal recovery by steam stimulation in heavy oil reservoirs". Spe Asia Pacific Enhanced Oil Recovery Conference, Kuala Lumpur, Malaysia, 2015, pp. 1-17.

8. Liu, D. X., Shi, X. F., Zhong, X., Zhao, H. T., Pei, C., Zhu, T. Y., Zhang, F., Shao, M. L., Huo, G., "Properties and plugging behaviors of smectite-superfine cement dispersion using as water shutoff in heavy oil reservoir". Applied Clay Science, 147, 2017, pp. $160-167$

9. Wang, H. S., Tang, C. S., Gu, K., Shi, B., Inyang, H. I., "Mechanical behavior of fiber-reinforced, chemically stabilized dredged sludge". Bulletin of Engineering Geology and the Environment, 79(2), 2020, pp. 629-643.

10. Pu, S. Y., Zhu, Z. D., Wang, H. R., Song, W. L., Wei, R. J., "Mechanical characteristics and water stability of silt solidified by incorporating lime, lime and cement mixture, and SEU-2 binder". Construction and Building Materials, 214, 2019, pp. 111-120.

11. Cho, H. N., Shim, J. H., Park, J. Y., "Performance evaluation of solidification/stabilization of dredged sediment using alkaliactivated slag". Desalination and Water Treatment, 57(22), 2015, pp. $1-10$. 
12. Wang, D. X., Xiao, J., Gao, X. Y., "Strength gain and microstructure of carbonated reactive $\mathrm{MgO}$-fly ash solidified sludge from East Lake, China". Engineering Geology, 251, 2019, pp. 3747.

13. Wang, D. X., Xiao, J., He, F. J., Zhou, Y. D., "Durability evolution and associated micro-mechanisms of carbonated reactive MgO-fly ash solidified sludge from East Lake, China". Construction and Building Materials, 208, 2019, pp. 1-12.

14. Develioglu, I., Pulat, H. F., "Compressibility behaviour of natural and stabilized dredged soils in different organic matter contents". Construction and Building Materials, 228, 2019, pp. 116787.

15. Gu, Z., Hua, S. D., Zhao, W. X., Li, S. S., Gao, Z., Shan, H. T., "Using alkali-activated cementitious materials to solidify high organic matter content dredged sludge as roadbed material". Advances in Civil Engineering, 2018, 2018, pp. 2152949.

16. Wang, Z. H., Xiang, W., Wu, X. T., Cui, D. S., "Influences of alkaline oxidant on strength of cement-stabilized sludge". Chinese Journal of Geotechnical Engineering, 41(4), 2019, pp. 693-699.

17. Sha, F., Jin, Q., Liu, P., "Development of effective microfine cement-based grouts (EMCG) for porous and fissured strata". Construction and Building Materials, 262, 2020. pp. 120775.

18. Yao, W. J., Pang, J. Y., Liu, Y. S., "An experimental study of Portland cement and superfine cement slurry grouting in loose sand and sandy soil". Infrastructures, 3(2), 2018, pp. 9.

19. Avci, E., Mollamahmutoğlu, M., "UCS properties of superfine cement-grouted sand". Journal of Materials in Civil Engineering, 28(12), 2016, pp. ID 6016015.

20. Mirza, J., Saleh, K., Langevin, M., Mirza, s., Bhutta, M. A. R., Tahir, M. M., "Properties of microfine cement grouts at $4^{\circ} \mathrm{C}, 10^{\circ} \mathrm{C}$ and $20^{\circ} \mathrm{C}$ ". Construction and Building Materials, 47, 2013, pp. 1145 1153.

21. Mollamahmutoğlu, M., Avci, E., "Engineering properties of slagbased superfine cement-stabilized clayey soil". ACI Materials Journal, 115(4), 2018, pp. 541-548.

22. Mollamahmutoğlu, M., Avci, E., "Time-dependent shear strength behavior of superfine cement-stabilized clayey soil". ACI Materials Journal, 117(2), 2020, pp. 251-258.
23. Zheng, X. Y., Liu, X. X., Wu, J., Dong, Y., "Impact of ultra-fine cement on early compressive strength of cement stabilized soft soil”. Journal of Engineering Geology, 28(4), 2020, pp. 685-696.

24. Ghadir, P., Ranjbar, N., "Clayey soil stabilization using geopolymer and Portland cement". Construction and Building Materials, 188, 2018, pp. 361-371.

25. Jamsawang, P., Poorahong, H., Yoobanpot, N., Songpiriyakij, S., Jongpradist, P., "Improvement of soft clay with cement and bagasse ash waste". Construction and Building Materials, 154, 2017, pp. 61-71.

26. Lang, L., Liu, N., Chen, B., "Investigation on the strength, durability and swelling of cement-solidified dredged sludge admixed fly ash and nano- $\mathrm{SiO}_{2}$ ". European Journal of Environmental and Civil Engineering, 2020, pp. 1776160.

27. Solonenko, I., "The use of cement concrete pavements for roads, depending on climatic conditions". Technical Journal, 13(3), 2019, pp. 235-240.

28. Luo, P. P., Wang, S. R., Hagan, P., Huang, Q. X., Cao, C., Gamage, K., "Mechanical performances of cement-gypsum composite material containing a weak interlayer with different angles". Dyna, 94(4), 2019, pp. 447-454.

29. Qin, B., Rui, D. H., Wang, S. R., Ji, M. C., Zou, Z. S., "Experimental investigation on formation and evolution characteristics of frozen wall under salty groundwater seepage". Journal of Engineering Science and Technology Review, 13(6), 2020, pp. 99-107.

30. Chiu, C. F., Zhu, W., Zhang, C. L., "Yielding and shear behaviour of cement-treated dredged materials". Engineering Geology, 103(1), 2008, pp. 1-12.

31. Wang, D. X., Abriak, N. E., Zentar, R., "Strength and deformation properties of Dunkirk marine sediments solidified with cement, lime and fly ash". Engineering Geology, 166, 2013, pp. 90-99.

32. He, X. X., Chen, Y. J., Tan, X., Wang, S. Q., Liu, L., "Determining the water content and void ratio of cement-treated dredged soil from the hydration degree of cement". Engineering Geology, 279, 2020, pp. 105892. 